\title{
The new hgeoHNOR2020 altitude conversion model and the compatibility between altitudes and depths in the coastal zone (ALT-BAT)
}

* Roberto Teixeira Luz, Eduardo Michalzechen Liberal Xavier, Natália Vargas Lengruber, Marco Aurélio de Almeida Lima, Salomão Soares, Maíra Kronemberg Lima, Jéssica Caroline dos Santos Siqueira, Everton Gomes dos Santos, IBGE

Copyright 2021, SBGf - Sociedade Brasileira de Geofísica.

This paper was prepared for presentation during the $17^{\text {th }}$ International Congress of the Brazilian Geophysical Society held in Rio de Janeiro, Brazil, 8-11 November 2021.

Contents of this paper were reviewed by the Technical Committee of the $17^{\text {th }}$ International Congress of the Brazilian Geophysical Society and do not necessarily represent any position of the SBGf, its officers or members. Electronic reproduction or storage of any part of this paper for commercial purposes without the written consent of the Brazilian Geophysical Society is prohibited.

\section{Abstract}

The seamless integration of reference surfaces for heights and depths is an essential requirement for modeling the coastal morphodynamical processes, for the correct evaluation of the risks of coastal flooding caused by extreme meteorological events and global sea level rise associated with climate change, and for the development of the respective adaptation and mitigation strategies. The development of a unified, high resolution digital topo-bathymetric model requires the integration of topographic and bathymetric data, eliminating discontinuities due to differences between the respective reference surfaces, usually linked to mean and minimum tidal levels, respectively. In Brazil, it is still not possible to accurately integrate the reference surfaces of the elevations given by the terrestrial cartography and the depths shown in the nautical charts, due to the lack of necessary information. To solve this problem, the fundamental height and gravity networks of the Brazilian Geodetic System (SGB) along the coast must be recovered, densified, and complemented with other types of measurements (sea level, airborne gravimetry, ocean altimetry, high resolution shallow bathymetry etc.), allowing the refinement of hydrodynamic, gravimetric and topographic models. Only after reaching these three goals will be possible to make a rigorous transformation between the various reference levels demanded in the coastal zone (vertical datum, chart datum, present mean/minimum/maximum levels etc.) and determine an ideal "flood line" as an intersection between the projected maximum water level and the topographic surface. Therefore, it is an interinstitutional, multidisciplinary task, demanding a high-level coordination.

To deal with these challenging characteristics, the Committee for the Integration of Terrestrial and Maritime Vertical Components (CICVTM) was created in 2015 within the National Cartography Commission (CONCAR). Before the extinction of CONCAR in 2019, CICVTM successfully performed a scientific diagnostic which allowed the design of pilot projects to study the different aspects and options for the altimetry-bathymetry (ALT-BAT) integration in the Brazilian coastal zone. One of the pilot projects was initially focused on the establishment of a high precision vertical reference network based in geodetic leveling, gravimetry and GNSS, called Coastal Geodetic Reference Network (RGRC), linking three long-term sea level stations along the coast of Rio de Janeiro State. After its completion by IBGE, such a geodetic infrastructure would serve as a basis for the integration of other elements, like hydrodynamic models and airborne surveys, to be carried out by other institutions within CICVTM. RGRC was included in the so-called REALT-2018, the first geopotential adjustment of the entire high precision vertical network (RAAP) of SGB, which released normal heights characterized by a complete treatment of the gravity effects on leveling. These heights represented an evolution with respect to the former heights, known as normal-orthometric, in which only the theoretical gravity was considered. Following this development, IBGE recently released the new model hgeoHNOR2020 for the conversion of geometric heights from GNSS surveys into normal heights compatible with REALT-2018. Despite not being a gravimetric geoid model, hgeoHNOR2020 delivers converted normal heights with increased consistency relative to the reference surfaces used along coastal zone, as discussed in this presentation. 